\title{
The Era of Digital Enablement: A Blessing or a Curse?
}

\author{
Anne-Laure Mention \\ anne-laure.mention@rmit.edu.au | RMIT University, Australia \\ Marko Torkkeli \\ marko.torkkeli@lut.fi | Lappeenranta University of Technology, Finland \\ João José Pinto Ferreira \\ jjpf@fe.up.pt | INESC Technology and Science, Faculty of Engineering, University of Porto, Portugal
}

There is nothing permanent except change.

Heraclitus

A few months ago, we claimed that COVID-19 had the potential to be a catalyst for change and innovation (Mention et al., 2020). Undeniably, this has indeed eventuated, but to a scale that was unforeseeable and unpredictable to many. Over the last few months, the world has literally changed. Around the world, people and communities have seen their lives put on standstill, experiencing and experimenting with variable levels of restrictions preventing social interactions. We have learned what physical - rather than social, at least initially - distancing meant and have uncovered new ways of doing things. And that applied to almost for every single aspect of life.

From the early days, we have observed myriads of technological novelties - some emerged as a result of the repurposing of existing technologies and products, and others from new combinations of technological advances. For instance, the Continuous Positive Airway Pressure (CPAP) devices were manufactured through the collaborative efforts of academics at the University College London's Institute of Healthcare Engineering and Mercedes-AMG HPP through reverse engineering of already existing technologies. The devices deliver oxygen directly to patients' lungs without the need of a ventilator which has reduced demand of ventilators, freed-up ventilators and complimented health delivery in the face of the pandemic. Across the Atlantic, the Fitbit Flow was created, in collaboration with Oregon Health \& Science University clinicians, based on the MIT e-vent design toolbox (RT, 2020; Walsh, 2020).

Beyond tangible innovations, new ways of organizing also emerged rapidly. Platforms allowing supply and demand for personal protection equipment (PPE) blossomed, unveiling the potential 
of digital technologies to quickly assist in addressing key conjunctural societal challenges. The world's largest community-driven GetUsPPE (n.d.) emerged as a swift and efficient response to the PPE shortage, by bringing together a diverse set of community stakeholders, while continentwide innovation hackathons brought together over 30,000 of prospective inventors and innovators across Europe and generated over 2,100 innovative solutions (EU Commission, 2020). The scale and speed at which those initiatives started, organically grew and delivered tangible results, are just unprecedented.

Commonalities across those novelties relate to the ingenuity demonstrated by virtual -and frequently, global - teams involved in their development, as well as the pace at which the innovation process occurred. This has further highlighted the collaborative nature of innovation, as well as the role played by digital technologies to support, facilitate, catalyse and accelerate this process.

In the world of work, many of our beliefs, conceptions and practices have been challenged. The prevalence of telework, for example, had remained a mostly occasional - if not anecdotal - work practice in the pre-covid world, with about $5 \%$ of the employed workforce usually working from home, and a mere $9 \%$ occasionally doing so, across European countries (Eurostat, 2020). In many work environments, telework used to be perceived as a perk, reserved to the privileged few, usually from the knowledge-intensive business services industries, who were benefitting from the autonomy allowing them to conduct their duties remotely and had the ability to do so. Suddenly, it became the norm for millions of workers worldwide, and levels of remote working simply skyrocketed - recent estimates indicate it affected over $40 \%$ of the workforce across Europe (Ahrendt et al., 2020). The shift to remote working might have become the norm, following the lead of companies like Facebook (Newton, 2020).

Activities that were previously deemed to require face-to-face interactions have been delivered in an exclusively virtual mode for several months now. Interestingly, that transition occurred with limited, if any, perceived productivity losses. A survey on employee sentiment by the Boston Consulting Group (2020) highlights that an overwhelming proportion of employees considered that the transition to remote working positively affected their productivity, at least for individual and managerial tasks. Collaborative tasks however were found to suffer a perceived productivity loss when delivered in a fully virtual mode. This may seem counterintuitive when taking stock on how most COVID-19 novelties were rapidly developed - i.e. by virtual and global teams enabled by and collaborating with digital technologies. Yet, this also raises topical questions on the perceptions of the importance of face-to-face, in person, interactions for collaboration, and whether those perceptions are influenced by our mental models, frameworks and past experiences, as well as on the persistence of those beliefs and perceptions as we transition to new ways of working and interacting.

Global surveys (e.g. Global Workplace Analytics, 2020) indicate that future working-from-home levels are likely to remain at much higher levels than in pre-covid times, as a result of an increasing demand both of the workforce and of employers, taking into consideration the cost saving opportunities those generate, as well as other impacts on flexible work practices, sustainability and disaster preparedness. Those trends call for a better understanding of the many facets of collaborative workplace in virtual and hybrid modes, ranging from the recreation of environ- 
ments conducive to serendipitous encounters, to maintaining team cohesion or nurturing trust for collaboration when dealing with virtual teams globally dispersed. Undoubtedly, the very nature of work is changing, with many contemplating the pros and cons of being tied to one versus affiliated with many, and leveraging the unique opportunities of remote working and adopting the digital nomad lifestyle. Some countries are committed to seize the opportunity to reverse the negative net migration trend (United Nations, n.d.) - Greece for example is enticing expats and returnees, offering them generous tax incentives (D'Aki, 2020).

Beyond the world of work, many so-called non-essential activities (and this notion of "non essential" is, in our view, highly debatable), their providers and their beneficiaries have had to reinvent themselves. Ever thought of trying virtual ski jumping in Holmenkollen, Norway, scuba diving in the Maldives or observing the endangered freshwater seals at Saimaa lake, Finland, during your holiday season? With about 90 percent of the world under travel restrictions at one point in 2020, many akin travellers took to virtual reality (VR), touring the Eiffel tower, to sights from Machu Picchu and the Galápagos Islands. Virtual tourism, enabled by digital technologies such as virtual reality, 3D live-stream-generating drones and video capabilities, has emerged as a partial substitute to tourism during the pandemic, yet the extent to which they will replace or simply complement the "real thing" (i.e. physical holidays and the memorable experiences of a traveller, see the editorial of our 2017 Winter issue) is unknown. Valeriy Kondruk, CEO of VR travel company Ascape, reported their VR apps downloads increase by 60 percent in early 2020, gathering interests from ancillary service providers such as airlines, educators and even nursing homes (National Geographic, 2020). Interesting, in a survey funded by UK based firm Oi2labs in collaboration with the European Network for Accessible Tourism (ENAT), it was found that 93 percent of respondents who said they had no previous experience with VR, also said they are willing to take up VR content creation, with 90 percent suggesting they would be willing to take up additional training (ENAT, 2020).

What all those illustrations highlight though, is the fact that digital technologies have become more pervasive than ever in our daily lives - whether they are supporting the development of cutting-edge healthcare innovations shaping our early response to the current pandemic, empowering us to do our daily jobs or dreaming of currently inaccessible journeys and discoveries. But it also informs us on the wealth of opportunities that can be unlocked through these technologies, and to a lesser extent, on their impact on us, as human beings - and on the value(s) of diversity, inclusion, as well as on the experiences we draw and build from human to human interactions and their richness. Voices and concerns are raising, globally - call it the "social dilemma", the ethics of AI or else, the real issue is to what extent those digital technologies are shaping us, as humans, and our behaviours and how much we truly connect with each other and are able to maintain, sustain or extend our social capital digitally. Long term impacts are yet to be explored - on our mental health, on the cognitive and affective development of kids around us, on seniors who tend to be left out by the digital transformation of our societies - but there is no doubt that we are currently witnessing a significant and profound change in society. And the jury is still out there to assess whether this is for the better or for the worst.

As we are all changing, JIM is also evolving. We are keeping faithful to our core values and intent - publishing high quality, multi/inter/cross/trans-disciplinary research on innovation and its management, accessible to and for all. We are however shortly introducing some novelties, 
such as the publication of short position papers that are built on funded research proposals in their early stage of implementation, and scheduling our transition to virtual issues, by releasing articles on our website, as soon as these have been accepted, thus accelerating their dissemination. In the spirit of Open Science.

Innovatively yours,

Anne-Laure Mention, Marko Torkkeli, João José Pinto Ferreira

Founding Editors

\section{References}

Ahdrendt, D., Cabrita, J., Clerici, E., Hurley, J., Leoncikas, T., Mascherini, M., Riso, S., Sandor, E., 2020. 'Living, working and COVID-19', Eurofound, 28 September, Eurofound, viewed 8 December 2020, Retrieved from: https://www.eurofound.europa.eu/publications/report/2020/ living-working-and-covid-19.

Boston Consulting Group, 2020. 'What 12,000 employees have to say about the future of remote work', Boston Consulting Group, 11 August, viewed 8 December 2020, Retrieved from: https://www.bcg.com/en-au/publications/2020/valuable-productivity-gains-covid-19.

D'Aki, L., 2020. 'Not just sea \& sand: Greek tax breaks lure expats, returness', Bloomberg, 12 Nov, viewed on 8 December 2020, Retrieved from: https://news.bloombergtax.com/ daily-tax-report-international/greece-seeks-to-lure-workers-from-abroad-with-new-tax-incentives.

ENAT, 2020. 'COVID-19 and opportunities for VR based tourism economy', European Network for Accessible Tourism, 15 May, viewed 8 December 2020, Retrieved from: https://www. accessibletourism.org/?i=enat.en.news. 2176 .

EU Commission, 2020. 'EU vs Virus challenge', European Innovation Council, 2 June, viewed 8 December 2020, Retrieved from: https://www.euvsvirus.org/.

Eurostat, 2020. 'How usual is it to work from home?', Eurostat, 24 April, viewed 8 December 2020, Retrieved from: https://ec.europa.eu/eurostat/web/products-eurostat-news/-/DDN20200424-1.

Get Us PPE, n.d. About, viewed 8 December 2020, Retrieved from: https://getusppe.org/ mission.

Global workplace analytics, 2020.'Work-at-home after COVID-19 - our forecast', Global Workplace Analysis, viewed 8 December 2020, Retrieved from: https://globalworkplaceanalytics. com/work-at-home-after-covid-19-our-forecast.

Mention, A.L., Ferreira, J.J.P. and Torkkeli, M., 2020. Coronavirus: a catalyst for change and innovation. Journal of Innovation Management, 8(1), pp. 1-5.

Mention, A.L., Ferreira, J.J.P. and Torkkeli, M., 2017. The Tourist and the Traveller: Embracing the Paradoxes of Innovation. Journal of Innovation Management, 5(4), pp.1-5. 
National Geographic, 2020. 'Is virtual travel here to stay, even after the pandemic subsides?', 20 April, viewed 8 December 2020, Retrieved from: https://www.nationalgeographic.com/travel/ 2020/04/can-virtual-reality-replace-real-tourism-during-pandemic-and-beyond/.

Newton, C., 2020, 'Facebook says it will permanently shift tens of thousands of jobs to remote work', The Verge, 21 May, viewed 8 December 2020, Retrieved from: https://www.theverge.com/ facebook/2020/5/21/21265699/facebook-remote-work-shift-workforce-permanent-covid-19mark-zuckerberg-interview.

RT, 2020. 'Fibit launches emergency ventilator for use during COVID-19 pandemic', RT, 6 June, viewed 8 December 2020, Retrieved from: https://rtmagazine.com/disorders-diseases/ critical-care/icu-ventilation/fitbit-emergency-ventilator-emergency-covid-19-pandemic/.

United Nations, n.d. 'World population prospect', Macrotrends, viewed on 8 December 2020, Retrieved from: https://www.macrotrends.net/countries/GRC/greece/net-migration\#: \{\}$:$ text= The\%20net\%20migration\%20rate\%20for,a\%2014.06\%25\%20decline\%20from\%202016.

Walsh, F., 2020. 'Coronavirus: Mercedes F1 to make breathing aid', BBC News, 29 March, viewed 8 December 2020, Retrieved from: https://www.bbc.com/news/health-52087002. 